\title{
Manual differential count and automated differential leukocyte count in normal individuals: a comparative study
}

\author{
Mahesh Man Bajimaya, Narayan Bahadur Mahotra, Lava Shrestha, Sait Pradhan, Neha Malla, Sabita \\ Kandel, Sonam Chaudhary, Sanyukta Gurung
}

\section{Author(s) info:}

Department of Clinical Physiology, Maharajgunj Medical Campus, Institute of Medicine, Maharajgunj, Kathmandu, Nepal

\section{Correspondence:}

Dr. Narayan Bahadur Mahotra

Email:

narayanmahotra@gmail.com

DOI :

https://doi.org/10.3126/jpsn.v2i1.42289

\begin{abstract}
Introduction: Differential leukocyte is a frequently ordered laboratory test. It is the percentage distribution of types of leukocytes on a stained film. There are two methods to determine differential leukocyte count which are manual and automated. Manual method is considered the gold standard and is used to validate differential counts obtained by automated method. The comparative knowledge about the different methods to determine differential leukocyte count may guide us to use of proper method to determine the differential count more accurately and in a shorter time. The study aims to compare differential leukocyte count of normal blood samples by manual and automatic methods.
\end{abstract}

Materials and methods: A cross-sectional, analytical study was conducted in laboratory of Kasturba Hospital, Manipal. A total of 347 blood samples of adults that did not show abnormalities in automatic analyzer were included in the study by purposive sampling method. Blood smears for manual count were prepared by Leishman's stain.

Results: A significant difference was observed between manual and automated leukocyte differential counts in 100 and 200 cells per specimen in neutrophils, lymphocytes, monocytes, eosinophils and basophils.

Conclusions: The study concludes the need of improving accuracy and reliability of the automated methods. A reference range generated by further studies could help provide more accurate determination of differential leukocyte count.

Keywords: Automated method, differential leukocyte count, manual method.

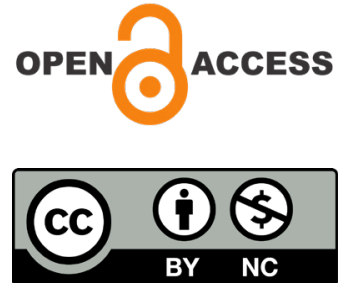

C $J P S N$ 


\section{INTRODUCTION}

Differential leukocyte is one of the most frequently ordered laboratory tests since decades.[1] It was first introduced by Ehrlich more than a century ago. [2] Leukocyte differential count is the percentage distribution of different types of leukocytes on a stained film.[3] It is used to identify abnormalities in the distribution like in infection and to identify morphological abnormalities.[4] There are two methods available to determine differential leukocyte count - manual and automated. Automated differential counts have the advantage of precision, efficiency, safety and economy.[5] Manual methods are still performed in laboratories that do not have access to automated hematology analyzers. Manual method is used to validate differential counts obtained with other methods.[6]

The comparative knowledge about the automated and manual differential leukocyte count could suggest us the proper method to determine the differential count in a more timely and accurate manner. This study aims to compare differential leukocyte count of normal blood samples by manual and automatic methods, to assess improvement by manual counts of 200 cells rather than 100 cells and to compare the differential leukocyte count done manually by two individuals.

\section{MATERIALS AND METHODS}

This is a cross-sectional, analytical study. The study was conducted in laboratory of Kasturba Hospital, Manipal from May 2006 to October 2007 after the ethical approval was obtained from Institutional Review Committee of Kasturba Medical College, Manipal. Permission of access to the blood samples was granted by laboratory of Kasturba Hospital, Manipal.

A total of 347 blood samples of adults that did not show abnormalities in automatic analyzer (Pentra XL 80, a product of Horiba ABX Diagnostics, Japan) were included in the study by purposive sampling method. Inadequate or blood samples of adults that showed abnormalities in the automatic analyzers were excluded from the study. Blood smears were prepared from samples and stained by Leishman's stain and manual differential leukocyte count was done on dried blood smears. Battlement method was used to count the 100/200 cells with the aid of a microscope using a cell counter.

Analysis was performed using SPSS version 10. The mean and standard deviation of continuous variables were calculated. Paired sample ' $\mathrm{t}$ ' test was used to compare the means. A ' $\mathrm{p}$ ' value of $<0.05$ was considered statistically significant.

\section{RESULTS}

Among the 347 samples paired t-test was used to compare the manual and automated leukocyte differential count.

A significant difference was observed between manual and automated leukocyte differential counts in 100 cells per specimen in neutrophils, lymphocytes, monocytes and eosinophils. The automated counts of monocytes and eosinophils were consistently higher than manual counts as illustrated in table 1 .

A significant difference was also observed between manual and automated leukocyte differential counts in 200 cells per specimen in neutrophils,

Table 1: Paired ' $\mathrm{t}$ ' test between manual and automated leukocyte differential count (100 cells per specimen and 200 cells per specimen)

\begin{tabular}{|c|c|c|c|c|c|c|c|c|c|c|c|c|}
\hline \multirow[t]{2}{*}{ Cells } & \multirow{2}{*}{$\begin{array}{c}\text { Mean of } \\
\text { Differences } \\
\text { of Counts }\end{array}$} & \multirow[t]{2}{*}{ SD } & \multicolumn{2}{|c|}{$\begin{array}{c}95 \% \text { CI of the } \\
\text { Difference }\end{array}$} & \multirow{2}{*}{$\begin{array}{c}\mathrm{T} \\
\text { value }\end{array}$} & \multirow{2}{*}{$\begin{array}{c}P \\
\text { value }\end{array}$} & \multirow{2}{*}{$\begin{array}{c}\text { Mean of } \\
\text { Differences } \\
\text { of Counts }\end{array}$} & \multirow[t]{2}{*}{ SD } & \multicolumn{2}{|c|}{$\begin{array}{c}95 \% \mathrm{CI} \text { of the } \\
\text { Difference }\end{array}$} & \multirow{2}{*}{$\begin{array}{c}\mathrm{T} \\
\text { value }\end{array}$} & \multirow{2}{*}{$\begin{array}{c}P \\
\text { value }\end{array}$} \\
\hline & & & Lower & Upper & & & & & Lower & Upper & & \\
\hline Neutrophils & -2.36 & 6.99 & -16.4 & 11.6 & 6.28 & .00 & -2.47 & 6.31 & -15.1 & 10.2 & 7.3 & 0.00 \\
\hline Lymphocytes & -2.10 & 7.79 & -17.6 & 13.5 & 5.03 & .00 & -2.12 & 7.5 & -17.1 & 12.9 & 5.4 & 0.00 \\
\hline Monocytes & 3.21 & 1.99 & -0.8 & 7.2 & -29.88 & .00 & 3.38 & 1.62 & .14 & 6.6 & -39 & 0.00 \\
\hline Eosinophils & 1.33 & 1.71 & -2.1 & 4.7 & -14.47 & .00 & 1.44 & 1.45 & -1.5 & 4.3 & -18.6 & 0.00 \\
\hline Basophils & -0.02 & 0.46 & -0.9 & 0.9 & .67 & .50 & -0.018 & .40 & -0.02 & 0.8 & 0.8 & 0.40 \\
\hline
\end{tabular}


Table 2: Paired ' $\mathrm{t}$ ' test between leukocyte differential count (100 cells per specimen) of manual counts by two individuals on 200 samples

\begin{tabular}{|l|c|c|c|c|c|c|}
\hline \multicolumn{1}{|c|}{ Cells } & $\begin{array}{c}\text { Mean of Differences } \\
\text { of Counts }\end{array}$ & $\begin{array}{c}\text { Standard } \\
\text { Deviation }\end{array}$ & \multicolumn{2}{|c|}{$\begin{array}{c}\text { 95\% Confidence Interval of } \\
\text { the Difference }\end{array}$} & T value & P value \\
\hline Neutrophils & -2.30 & 9.68 & -21.66 & 17.06 & 3.35 & .00 \\
\hline Lymphocytes & 3.10 & 9.21 & -15.32 & 21.52 & -4.79 & .00 \\
\hline Monocytes & -0.34 & 2.16 & -3.98 & 4.66 & 2.23 & .03 \\
\hline Eosinophils & -0.34 & 2.19 & -4.04 & 4.72 & 2.30 & .02 \\
\hline Basophils & 0.60 & 1.12 & -1.64 & 2.84 & -7.64 & .00 \\
\hline
\end{tabular}

lymphocytes, monocytes, eosinophils and basophils as shown in table 1.

A significant difference was observed between manual counts of differential leukocyte count in 100 cells per specimen by two individuals on 200 samples in neutrophils, lymphocytes, monocytes, eosinophils and basophils as illustrated in table 2 .

A comparison was done between manual cell counts of 100 cells performed by an experienced technician and automated cell counts in 200 samples. There was no significant difference in neutrophils ( $\mathrm{t}=-0.7, \mathrm{p}=0.94$. However, a significant differences were observed in lymphocytes $(\mathrm{t}=10.51$, $\mathrm{p}=0.94)$, monocytes $(\mathrm{t}=-24.77, \mathrm{p}=0.00)$, eosinophils $(\mathrm{t}=-13.18, \mathrm{p}=0.00)$ and basophils $(\mathrm{t}=8.42, \mathrm{p}=0.00)$.

\section{DISCUSSION}

In this study, a significant difference was observed between manual and automated leukocyte differential counts. Similar to this study, Sharma et al. also showed similar results in 100 manual counts compared with automated counts done using Sysmex XN550 L-series. The neutrophils, lymphocytes, monocytes and eosinophils showed a significant difference with $\mathrm{p}$ value $=0.000$ and in contrast to this study basophils also showed a significant difference with $\mathrm{p}$ value $=0.000 .4$ Similarly, a study conducted by Rimarenko et al. reported 10 false positive among 63 patients with normal 100 cells manual differential count by Counter S-Plus IV.[7] Kratz et al. also reported 9.2\% samples had difference in value in automated differential count conducted by Cella Vision DM96 among the 120 samples verified by 100 cells manual differential count.[8]
In contrast to this study, Kim et al. reported mean difference between 200 cells manual and automated count by Symex DI-60 in neutrophills 2.06 and lymphocytes -0.91 . However, mean difference in monocytes (-1.65), eosinophils (-1.77) and basophils (1.03) was similar to this study.[9]

In order to assess accuracy, the test needs to be compared against a gold standard which is manual differential cell count.[6] The study was conducted in a single center hence, the results may not represent results from other centers nationwide. A larger sample size including more centers selected by randomized sampling could provide a more accurate finding.

\section{CONCLUSION}

The study observed a significant difference in manual and automated differential leucocyte counts with 100 cells per sample and 200 cells per sample. The study concluded that accuracy and reliability of the automated methods need to be improved and a reference range generated by further studies could help provide more accurate determination of differential leukocyte count.

\section{CONFLICT OF INTEREST}

None.

\section{REFERENCES}

1. Allen JK, Batjer JD: Evaluation of an Automated Method for Leukocyte Differential Counts Based on Electronic Volume Amalysis. Arch Pathol Lab Med 1985; 109: 523.

2. Kay AB. Paul Ehrlich and the Early History of 
Granulocytes. Microbiol Spectr. 2016 Aug;4(4): 1-13.

3. Platt WR: Critical Examination of the Stained Smear. In: Color Atlas and Textbook of Hematology. J.B Lippincott Company, Philidelphia: Blackwell Scientific Publication, Oxford 1960, P 98.

4. Sharma A, Lone AH, Kaur R, Nijhawan VS. Comparative Analysis of Leucocyte Count (Total and Differential) in Patients with Leucocytosis using Sysmex XN550-L Series (5 Part) Automated Analyzer and Conventional Manual Technique in a Tertiary Care Hospital in Rural Haryana. JK Sci. 2020;22(2):4.

5. Morse EE, Nashed A, Spilove L: Automated Differential Leukocyte Counts. Ann Clin Sci 1989; 19(3): 155-160.

6. Finn LS, Hall J, Xu M, Rutledfe JC: Flow Cytometric
Clinical Chemistry 1997; 43: 1085-1088.

7. Rimarenko S, Castella A, Salzberg MR, Strand CL. Evaluation of the automated leukocyte differential count in emergency department patients. Am J Emerg Med. 1987 May 1;5(3):187-9.

8. Kratz A, Bengtsson H-I, Casey JE, Keefe JM, Beatrice GH, Grzybek DY, et al. Performance Evaluation of the CellaVision DM96 System: WBC Differentials by Automated Digital Image Analysis Supported by an Artificial Neural Network. Am J Clin Pathol. 2005 Nov;124(5):770-81.

9. Kim HN, Hur M, Kim H, Kim SW, Moon H-W, Yun Y-M. Performance of automated digital cell imaging analyzer Sysmex DI-60. Clin Chem Lab Med CCLM. 2017 Nov 27;56(1):94-102. 